\title{
Overt Primary Myelofibrosis
}

National Cancer Institute

\section{Source}

National Cancer Institute. Overt Primary Myelofibrosis. NCI Thesaurus. Code C41238.

Primary myelofibrosis characterized by reticulin or collagen fibrosis in the bone marrow. The bone marrow is usually normocellular or hypocellular. Myeloblasts account for less than $10 \%$ of the bone marrow cells. Atypical megakaryocytes are present. 